\title{
Effects of power frequency voltages on amputated human limb
}

\author{
A. O. CARTER AND R. MORLEY \\ Department of Electrical Engineering, The University of Newcastle upon Tyne, and the \\ Medical Branch, H.M. Factory Inspectorate, Newcastle upon Tyne
}

\begin{abstract}
Carter, A. O., and Morley, R. (1959). Brit. J. industr. Med., 26, 224-230. Effects of power frequency voltages on amputated human limb. Electric voltages of between 40 and $500 \mathrm{~V}$ at $50 \mathrm{~Hz}$ and 120 and $240 \mathrm{~V}$ direct were applied to freshly amputated mid-thigh legs connected to a heart-lung machine. Current and voltage were recorded against time.

The direct currents showed a rise of current with time and caused little skin damage. The make and break of the current caused contractions of the muscles.

The alternating currents produced by voltages between 30 and $80 \mathrm{~V}$ showed a steady rise with progressive skin damage. With alternating voltages of 250 and $500 \mathrm{~V}$ the current showed a rapid rise, with an equally rapid fall after a period of time. The current wave-form was nonsinusoidal and, after the fall, showed unidirectional impulses. Muscular contraction was tonic but later became clonic due to the impulses of current. This progression has been described in held-on electric shock accidents.
\end{abstract}

The currents, passed through human skin under certain alternating voltages, were measured (Carter and Morley, 1969) up to the point of skin destruction as part of an investigation into electric shock. The next step was to measure the current passed by a living body at voltages where considerable skin damage would occur. Such voltages have been applied to the limb of a volunteer (Freiberger, 1934) with suitable isolation or earthing technique but only for very short periods. No such limitations apply to an amputated limb and gross burning was produced. It will be appreciated that such conditions occur in accidental electric shock.

\section{Method}

In all cases the legs were mid-thigh amputations, undertaken in elderly patients for early gangrene of the toes. After removal by the surgeon in the theatre, the leg was immediately taken into the side-room where tapered PVC catheters ${ }^{1}$ were inserted and tied into the femoral artery and vein. The limb was perfused by means of a syringe with normal saline containing heparin $(125,000$ i.u. to the pint $(625 \mathrm{ml}$.) ). Approximately $500 \mathrm{ml}$. of saline were used for perfusion. The limb was then taken to the experimental room where two pints of matched compatible blood were available.

The limb was hung vertically on a stand with the foot uppermost (Fig. 1). The oxygenator ${ }^{1}$ was prepared by putting two pints of blood into the priming inlet (Fig. 2). The upper limb of the ' $z$ ' is filled with metal gauze and a filter. Oxygen is bubbled in through the blood at the base of the vertical column from a cylinder. The blood leaves the bag at this point and passes in PVC tubing through an electric finger pump with a variable speed gearbox. From here, it passes into the femoral artery, leaving the limb by the femoral vein, and is returned to the upper limb of the ' $z$ ' of the oxygenator.

As soon as the blood flow had been established, any bleeding points in the stump were tied off, or alternatively a ligature was tied round the stump about half an inch up. This was done mainly for cleanliness as the bleeding itself was not important and any blood lost could be returned to the circuit if required.

The leg and circulating blood were allowed to attain room temperature.

The electrical equipment used was described by

${ }^{1}$ The disposable regional perfusion oxygenator and PVC catheters were manufactured by Travenol Laboratories Inc., Morton Grove, Illinois, U.S.A. and supplied by Baxter Laboratories, Thetford, Norfolk. 


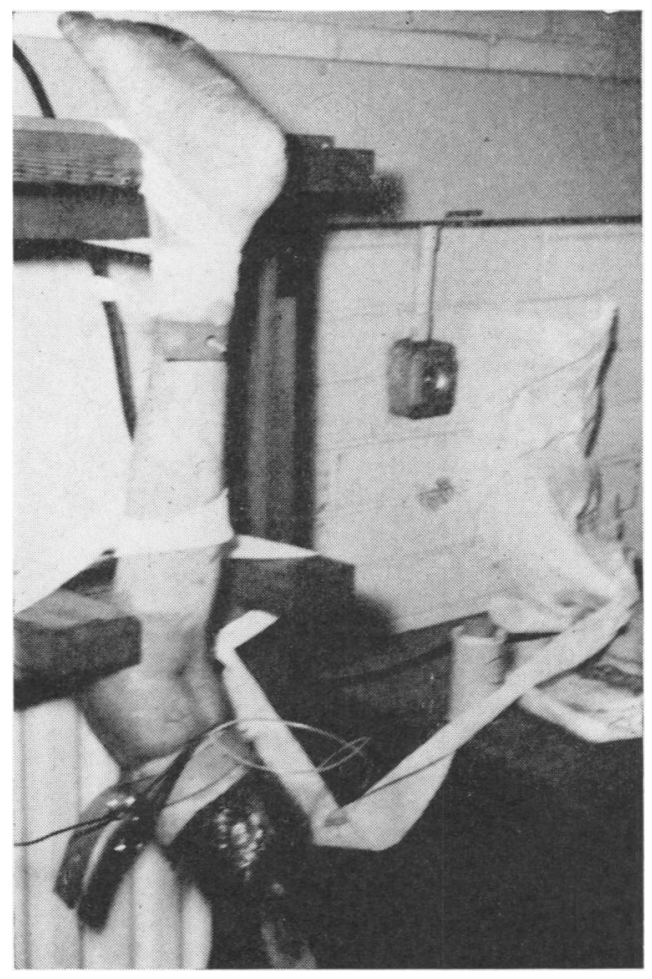

FIG. 1. Amputated leg on stand with cannulae inserted and electrodes in position. An alternating current is flowing and the muscles are contracted, as is shown by flexion of the knee.

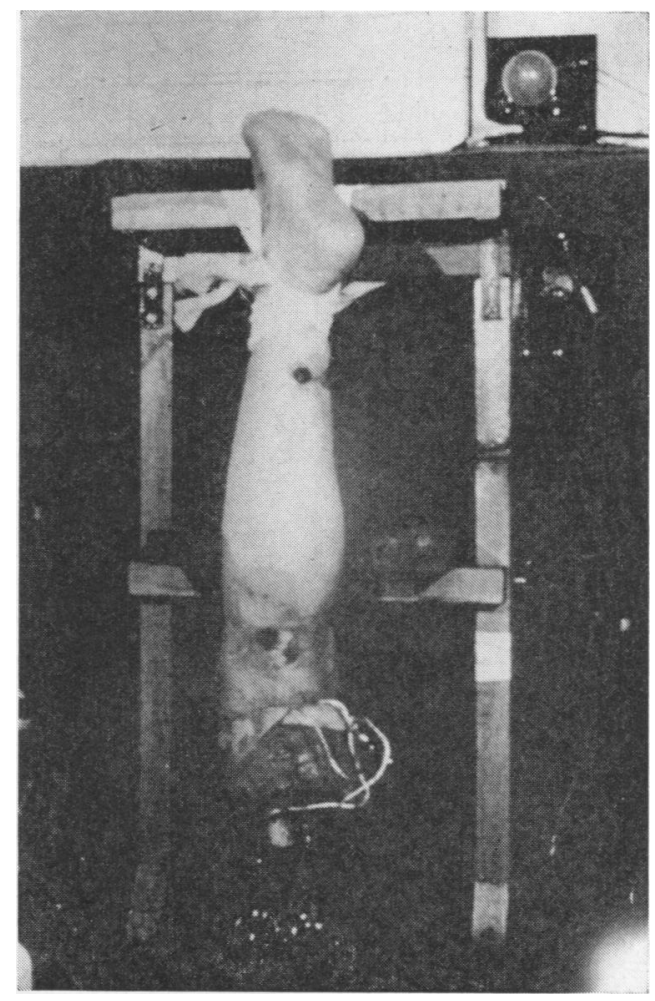

FIG. 3. Skin burns on leg from several electric shocks. 


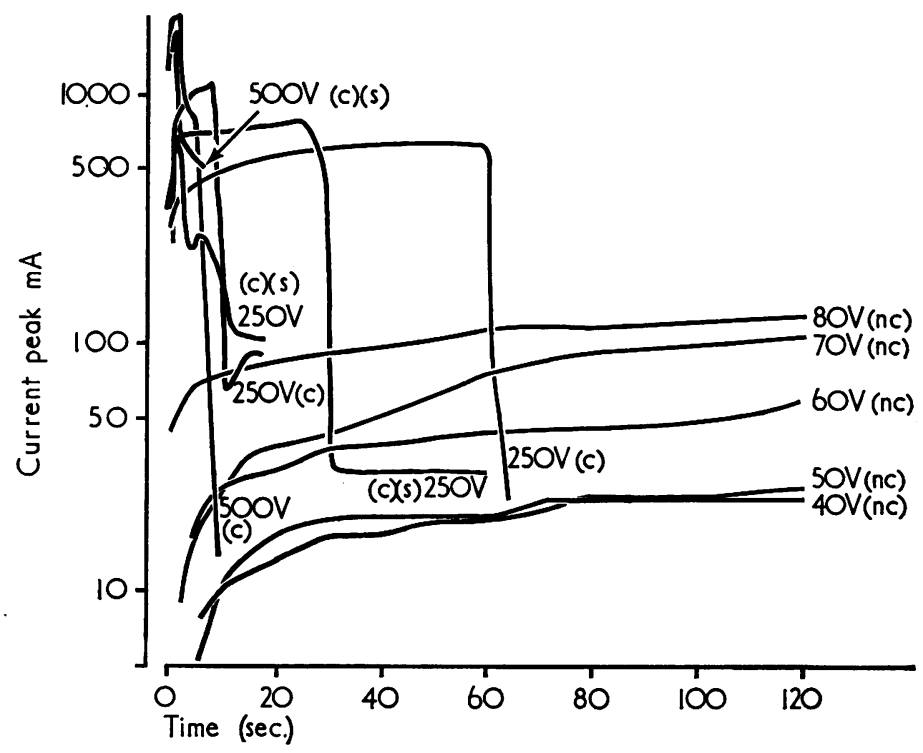

FIG. 4. Graphs of current against time for various $50 \mathrm{~Hz}$ applied r.m.s. voltages between 40 and $500 \mathrm{~V}(30 \mathrm{~V}$ gave no detectable current). The time scale is linear and the current scale is logarithmic:

(c) circulation established;

(c) (s) circulation stopped at moment of shock; (nc) no circulation established.

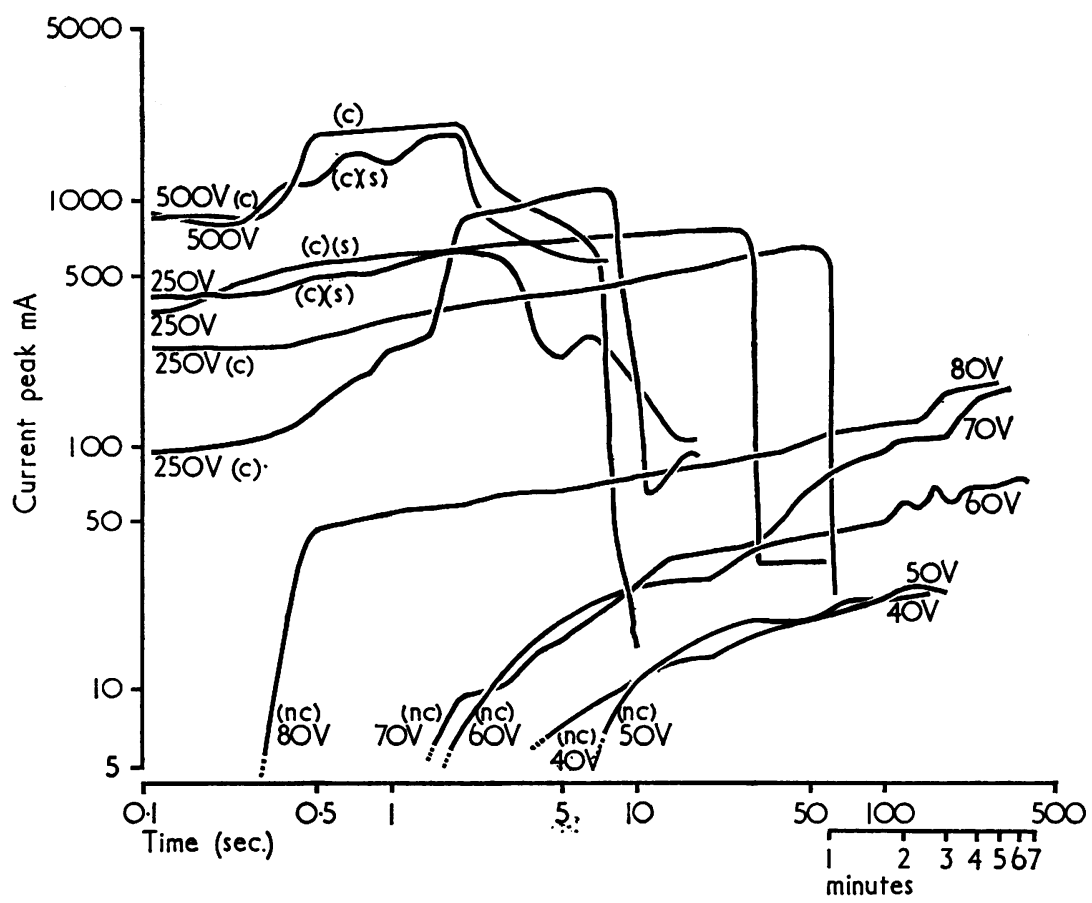

FIG. 5. Graphs as in Fig. 4 but with both scales logarithmic. 
Carter and Morley (1969). It was designed to operate at sensibly $( \pm 3 \%)$ constant voltage. Electrodes, $1 \cdot 3 \mathrm{~cm}$. diameter ( $2.84 \mathrm{sq} . \mathrm{cm}$.), were applied dry to the skin of the leg 2-3 cm. below the knee and above the ankle, and were held in place by rubber straps. A selected voltage was applied, and current, voltage, and time were recorded on the ultraviolet recorder. The current was allowed to continue either until the time period was outside the practical range of electric shock or until extensive burning had occurred (Fig. 3). Figures 4 and 5 do not necessarily show the end of each test. Both electrode positions were changed after each voltage application.

A cinematograph film in colour was taken of some of the limbs to relate the electrical measurements to colour changes, i.e., cyanosis, burning, and movement of the limb.

\section{Results}

Five legs were used. In two, it was not possible to establish a circulation, probably due to clotting in the femoral artery. It appears that this occurred almost immediately the leg was separated at operation and before it was washed clear with the heparinized saline. However, as the muscles still responded apparently normally to electrical stimuli, it was decided to carry on with the applications of the appropriate voltages. These two legs are noted in Figures 4 and 5.

It had been thought that there could be a marked difference between the results obtained whilst the circulation was flowing and when it was stopped at the moment of electric shock. No such difference was found, as will be seen in Figure 4.

In those limbs with a circulation, cyanosis was marked at the skin surface and in the effluent blood whilst the current was passing but re-oxygenation occurred rapidly once the current had ceased. With alternating voltages, vigorous muscular contraction occurred the whole time that the voltage was applied. The strength of the muscular contraction obtained at the end of an experimental session (approximately one hour after amputation) appeared just the same as those obtained at the beginning.

One leg was stimulated electrically 18 hours after amputation (17 hours after the circulation had ceased). No muscular contractions were observed.

The results are given in the form of graphs (Figs 4 and 5), and three reproductions of part of the ultraviolet recordings are shown in Figures 6, 7 , and 8. As with the skin alone (Carter and Morley, 1969), there is a slow rise of current with time when using the lower alternating voltages. At $250 \mathrm{~V}$ there was a rapid rise of current; charring occurred at half to one minute and was followed by a sharp fall in current. At $500 \mathrm{~V}$ the current rose and fell, with similar charring, in about a tenth of the time. The charring was preceded by blister formation which persisted at the edge of the electrodes.

The skin lesions under the electrodes consisted, as expected, firstly of blisters and then of charring with destruction of the blister except at the circumferance of the electrode, where the blister formed a ring a few millimetres external to the electrode. The effect was more rapid at the higher voltages (Fig. 3).

As shown in Figs 7 and 8, the sine wave-form of the current becomes irregular with pronounced peaks. The muscles responded when the alternating voltage was applied by a tonic contraction. With voltages of 250 and 500 , the contractions appeared to be maximal. When the charring of the skin and the fall in current occurred, the tonic contractions were replaced by clonic contractions. These latter appeared to coincide with the peaking of the current wave.

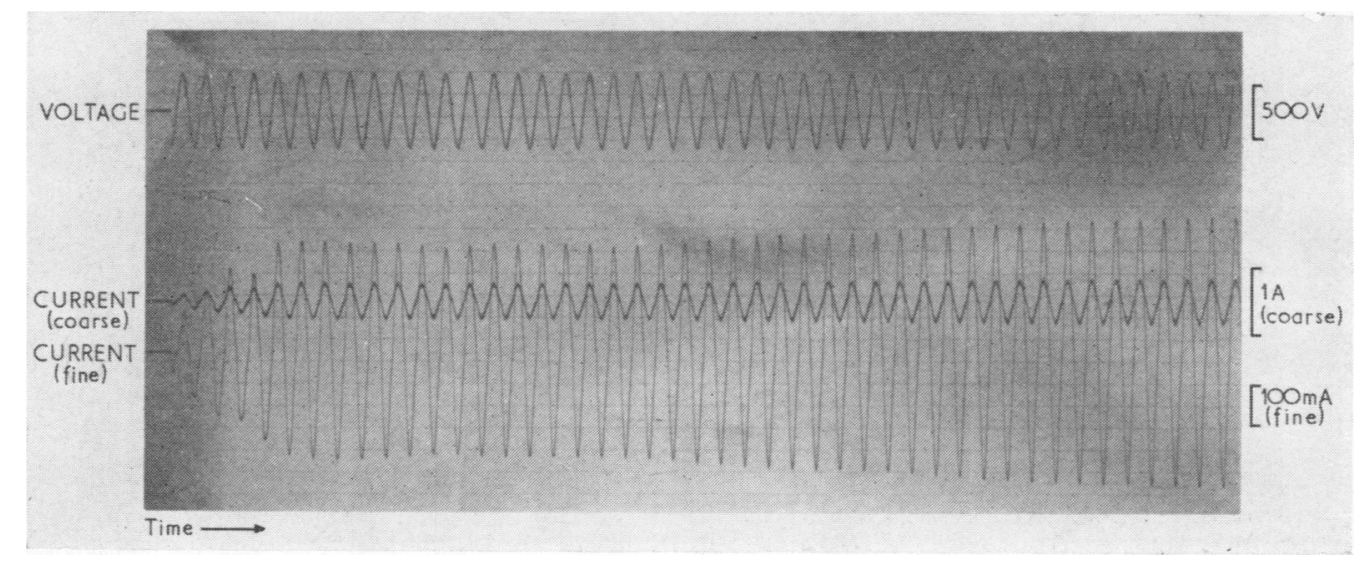

FIG. 6. Recording of voltage $(250 \mathrm{~V}$ r.m.s. at $50 \mathrm{~Hz})$ and current (two scales) in the first second of an electric shock. 
FIG. 7. Recording of voltage ( $250 \mathrm{~V}$ r.m.s. at $50 \mathrm{~Hz}$ ) and current (two scales) against time during a period when the current dropped suddenly. Spikes of current can be seen which cannot conveniently be shown in Figures 4 and 5 .

Direct current was not the subject of this investigation, but the opportunity was taken to make a measurement at two of the direct voltages commonly available. These are given in Fig. 9 but no comments are made because of the small number of curves. The muscles contracted only at the make and break of the current, the rise in current not being rapid enough to cause stimulation of the nerves or the muscles (Keele and Neil, 1965).

\section{Discussion}

Figures 4 and 5 present the change of current with time. The use of linear scales for both current and time would have made the information unreadable, and so logarithmic scales have been used to accommodate the large range of current. The linear time scale in Fig. 4 serves to emphasize the suddenness of some of the current changes whilst the logarithmic

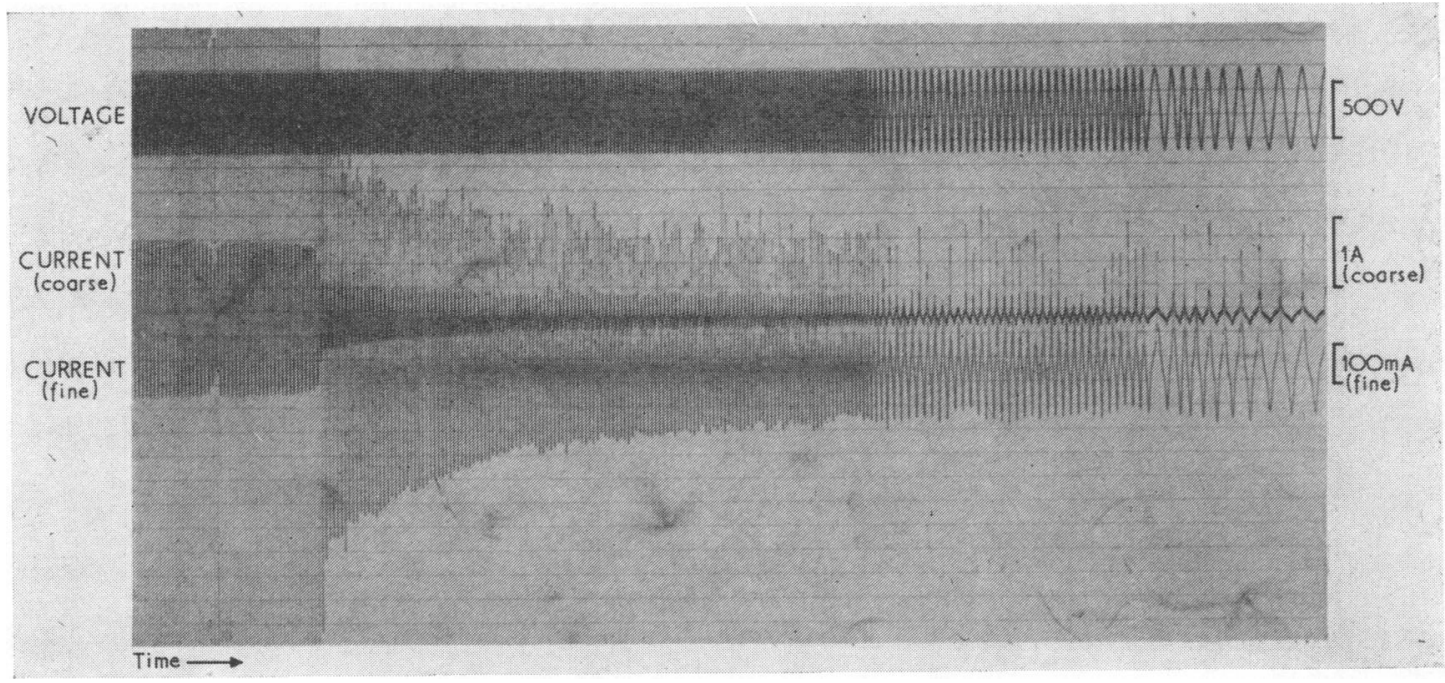

FIG. 8. As Fig. 7 but showing non-sinusoidal current waves. The paper speed was increased during the recording. 


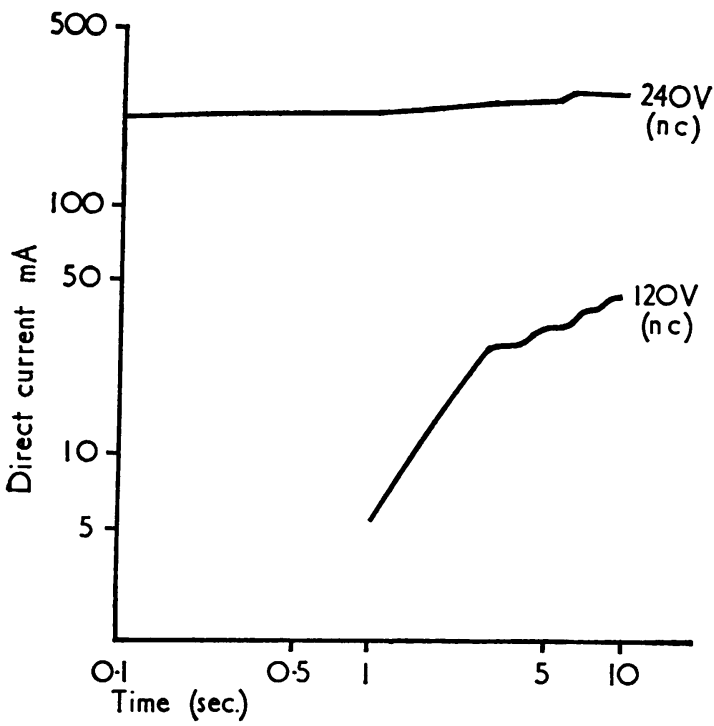

FIG. 9. Graphs of direct current against time at $120 \mathrm{~V}$ and $240 \mathrm{~V}$. Both scales are logarithmic.

time scale of Fig. 5 allows some of the detailed changes to be seen in the time range of 0.1 to 10 seconds. A time of $0 \cdot 1$ second represents 5 cycles of the supply frequency and, as can be seen in Fig. 6, there are significant changes in the current magnitude between one half-cycle and the next, almost a doubling between the first half-cycle and the second.

There was no attempt to control the point on the waveform at which the voltage was switched in. If the relative values in the resistor-capacitor circuit of Tregear (1966) are used, in conjunction with an internal resistance of the order of $500 \mathrm{ohms}$ for the leg, then a transient current with a time constant of less than one milli-second (1/20th of a cycle) could occur, but none is evident in Fig. 6, where the voltage initiation would favour its appearance.

The internal resistance of the leg can be taken as not greater than the minimum values of impedance deducible from Figs 4 and 5 (approximately 350 ohms).

Since this work was concerned with the magnitude of the currents, no attempt was made to measure the phase angle. Indeed the non-sinusoidal nature of the current makes such an attempt fruitless, although the peak current in each half-cycle appears to precede slightly the peak of the applied voltage.

The two sets of graphs show a marked difference in both magnitude and form between those for the lower voltages, i.e., 40 and $80 \mathrm{~V}$ r.m.s., and those for the higher voltages, namely 250 and $500 \mathrm{~V}$ r.m.s.

Particular attention must be drawn to the sudden drop in current that occurs after a variable time interval at 250 and $500 \mathrm{~V}$. The experiments did not stop at the apparent point indicated on the graph and the ultraviolet recordings continued. However, the wave-form had become so irregular (end of tracing in Figs 7 and 8) that, from the times shown, the current could not usefully be indicated on the graphs but may be seen on the recordings.

At the end of the recordings in Fig. 8, where the time scale has been expanded, it will be seen that the sine wave-form has been lost. In Fig. 7, the general level of the current has fallen by a factor of 10 but there occur large irregular peaks of current which on occasions are several times greater than the general level of current. The non-sinusoidal current in Fig. 7 and the spikes of current seen in Fig. 8 would be expected where organic material has been carbonized, and it is not unexpected to see signs of unilateral conduction (Pethig, 1968).

From observations and cinematograph film of the leg under stimulation it appeared that these peaks of current were responsible for the clonic contraction of the muscles. The progression from tonic to clonic muscular contractions occurs in 'held-on' shock. It will be described and discussed when electrical accidents are considered in a later paper. It suggests that, in such accidents, the clonic stage occurs when the current falls and a certain minimal skin damage has occurred (Fig. 3). Even at 250 and 500 V only local charring of the skin was produced. Later work to be published on electrocution cases, including examples of suicide where the victim has used electrodes similar to those described above, showed that such charred conditions could have persisted for several days without apparent change.

The paucity of curves is regretted but the number of legs was limited. Ideally, the authors would have liked to have curves for the voltages betwen 80 and $250 \mathrm{~V}$ at, say, $20 \mathrm{~V}$ intervals. This might have shown whether the lower voltage type of curve gradually changed to that of the higher voltages (250 and 500) or whether there was an abrupt change at some intermediate voltage.

The shapes of the graphs are of interest when 'held-on' currents in electrical accidents are considered. Taking the $500 \mathrm{~V}$ curve, it seems that, with a suitable contact area, a current that was sufficiently high to make the victim hold on, could fall significantly after about 10 seconds so that the victim could then release his grip. At the lower voltages shown, there was no sign of a large fall in current even after seven minutes, and a victim whose contact area allows him to be held on initially is unlikely to release himself.

Both Ferris, King, Spence, and Williams (1936) and Kouwenhoven and Milnor (1957) suggested that there is a range of current in which ventricular fibrillation is likely and another range in which 
cardiac arrest is likely, but that outside these ranges they become less likely. If the contact area and voltage are such that the current magnitude spends a significant time in these zones, both when rising and when falling, then it seems that the slow fall in current in this case could add to the danger of involvement of the heart.

This work was done with the aid of a grant from the Scientific Research Council. Our thanks are due to Dr. T. A. Lloyd Davies, H.M. Senior Medical Inspector of Factories, Professor R. L. Russell, Department of Electrical Engineering, Professor D. N. Walder, Department of Surgery, University of Newcastle upon Tyne, and Mr. A. H. Petty, Consultant Surgeon, Newcastle General Hospital, who have encouraged and assisted us in the work.

\section{References}

Carter, A. O., and Morley, R. (1969). Electric current flow through human skin at power frequency voltages. Brit. J. industr. Med. 26, 217-223.

Ferris, L. P., King, B. G., Spence, P. W., and Williams, H. B. (1936). Effect of electric shock on the heart. Electl. Engng. N.Y., 55, 498-515.

Freiberger, H. (1934). Der elektrische Widerstand des menschliche Körpers, p. 121. Springer, Berlin.

Keele, C. A., and Neil, E. (1965). Samson Wright's Applied Physiology, 11 th ed., p. 214. Oxford University Press, London.

Kouwenhoven, W. B., and Milnor, W. R. (1957). Field treatment of electrical shock cases-I. Trans. Amer. Inst. elect. Engrs. Part III (Power Apparatus and Systems), 76, 82-4.

Pethig, R. (1968). Organic semiconductors. Electronics and Power G.B. (J. Instn. elect. Engrs, 14, 271-4.)

Tregear, R. T. (1966). Physical Functions of Skin, 1st ed., p. 53-72. Academic Press, London.

Received for publication September 3, 1968. 